\title{
TINGKAT LITERASI KESEHATAN PASIEN DIABETES MELLITUS TIPE 2 DI PUSKESMAS KOTA TOMOHON
}

\author{
Vina Putri Patandung', Kusrini Kadar ${ }^{2}$, Kadek Ayu Erika ${ }^{3}$ \\ ${ }^{1,2,3}$ Magister Ilmu Keperawatan, Fakultas Keperawatan UNHAS, Makassar 90245 \\ Diterima : 6 Oktober 2018, Disetujui : 26 Oktober 2018 \\ e-mail : vinz_4jc@yahoo.co.id
}

\begin{abstract}
Background: Type 2 Diabetes Mellitus (T2DM) is a chronic disease with high level of complexity that requires extensive education and self-care management. The demands on individuals with T2DM are complicated by the fact that self-care often depends on printed educational materials and high health literacy skills. Every individual who needs health information and services also needs health literacy skills to find health information and services, communicating needs, respond to and using the information and obtaining health services, understanding health information, and finding realible health information and services to suit all needs, making the right decision to act. This study aims to determine the level of functional, communicative, and critical health literacy of T2DM patients at Pangolombian and Kakaskasen Public Health Centre of Tomohon City, as well as factors related to the level of health literacy. Method: Quantitative descriptive to describe the level of health literacy and correlation to see factors related to the patient's health literacy level. The sample of this study was a patient of T2DM who followed prolanis, amounted to 34 people, determined by using purposive sampling. Data were obtained by interview and using demographic characteristics questionnaire and Functional, Communicative, and Critical Health Literacy questionnaires. Result: Generally, health literacy level of T2DM patients is still low both for functional, communicative, and critical. This can happen because of various factors but the most related is the low access to health information and patient education level. Conclusion: The results of this study showed that health literacy level of T2DM patient in Tomohon city is still very low. This happened because access to health information is still less obtained by patients and also their education level is still low. These results can be used as recommendations for health workers to pay more attention to how to educate patients who should be adjusted to the level of education so that the information provided can be put to good use by the patient.
\end{abstract}

Keywords: Diabetes Mellitus Tipe 2; functional health literacy; communicative health literacy; critical health literacy

\section{PENDAHULUAN}

Penyakit diabetes saat ini bukan hanya menjadi krisis kesehatan melainkan sudah menjadi salah satu keadaan darurat kesehatan global terbesar di abad ke-21. Setiap tahun semakin banyak orang hidup dengan kondisi ini yang bisa berakibat pada komplikasi yang dapat mengubah hidup. Pada tahun 2017 terdapat 425 juta orang dengan usia 20-79 tahun yang menderita diabetes di seluruh dunia, dan diperkirakan terus meningkat hingga pada tahun 2045 mencapai 629 juta jiwa atau meningkat sebesar 48\%. Di Asia 
Tenggara pada tahun 2017 penderita diabetes sebanyak 82 juta jiwa dan pada tahun 2045 diperkirakan mencapai 151 juta jiwa atau meningkat sebesar $84 \%$. Indonesia sendiri naik peringkat dari peringkat 7 pada tahun 2015 menjadi peringkat 6 pada tahun 2017 dengan jumlah penderita sebesar 10,3 juta jiwa, dan diperkirakan terus meningkat hingga 16,7 juta jiwa atau sebesar $62,13 \%$ pada tahun 2045. Pada tahun 2017, mortalitas penyakit diabetes pada orang dewasa terbilang tinggi yaitu sekitar 3,2 hingga 5 juta jiwa (International Diabetes Federation [IDF], 2017a).

Diabetes melitus tipe 2 (DMT2) adalah bentuk diabetes yang paling umum dan sering terjadi pada orang dewasa. Di Indonesia khususnya di Sulawesi Utara, prevalensi penyakit DMT2 sebesar 3,6\% dan merupakan propinsi kedua setelah Sulawesi Tengah dengan prevalensi tertinggi penderita diabetes. Pada DMT2, tubuh mampu memproduksi insulin namun menjadi resisten sehingga insulin tidak efektif. Seiring waktu, tingkat insulin kemudian menjadi tidak mencukupi. Hal inilah yang menyebabkan kadar glukosa darah tinggi, baik itu karena resistensi maupun defisiensi insulin. Urbanisasi yang cepat, makanan yang tidak sehat dan peningkatan gaya hidup dengan aktivitas fisik yang kurang, menyebabkan terjadinya peningkatan obesitas dan DMT2. (Badan Penelitian dan Pengembangan Kesehatan Kementerian Kesehatan RI [Balitbang Kemenkes RI], 2013; IDF, 2017b; World Health Organization [WHO], 2016).

DMT2 dapat menyebabkan berbagai macam komplikasi apabila tidak dikelola dengan baik. Penderita DMT2 memiliki peningkatan risiko pengembangan sejumlah masalah kesehatan serius yang mengancam jiwa sehingga meningkatkan biaya perawatan medis dan menurunkan kualitas hidup. Tingkat glukosa darah yang terus-menerus tinggi dapat menyebabkan kerusakan pada pembuluh darah jantung, mata, ginjal dan saraf. Hal ini dapat menyebabkan penyakit kardiovaskular, serebrovaskular, neuropati, kebutaan, gagal ginjal dan amputasi pada anggota tubuh bagian bawah. Oleh karena itu penting untuk mencegah terjadinya komplikasi pada DMT2 (IDF, 2017; Liu, Fu, Wang, \& Xu, 2010; Stolar, 2010).

Komplikasi pada DMT2 dapat dicegah dengan memperhatikan perawatan pasien. American Diabetes Association [ADA] (2017) menyoroti pentingnya perawatan yang berpusat pada pasien yang didefinisikan sebagai perawatan yang sesuai dan responsif terhadap pilihan, kebutuhan, dan nilai pasien secara individual. Karakteristik sistem perawatan yang paling sukses adalah dengan membuat perawatan yang berkualitas tinggi sebagai prioritas. DMT2 merupakan penyakit kronis dengan tingkat kerumitan yang tinggi yang membutuhkan pendidikan dan manajemen perawatan diri yang ekstensif. Tuntutan pada individu dengan diabetes diperumit oleh kenyataan bahwa perawatan diri sering bergantung pada materi pendidikan yang dicetak dan instruksi lisan, serta memerlukan keterampilan health literacy yang tinggi (White, Wolff, Cavanaugh, \& Rothman, 2010).

Health literacy merupakan suatu keadaan dimana individu memiliki kapasitas untuk memperoleh, memproses, dan memahami informasi kesehatan dasar yang diperlukan untuk mengambil keputusan yang tepat tentang kesehatan. 
Setiap orang yang membutuhkan informasi dan layanan kesehatan juga membutuhkan keterampilan health literacy untuk menemukan informasi dan layanan kesehatan, mengkomunikasikan kebutuhan, menanggapi dan menggunakan informasi dan layanan kesehatan yang diperoleh, memahami pilihan, konsekuensi dan konteks dari informasi dan layanan kesehatan serta menentukan informasi dan layanan yang sesuai dengan kebutuhan dan preferensi mereka sehingga mereka dapat mengambil keputusan yang tepat untuk bertindak (Centers for Disease Control and Prevention [CDC], 2016).

\section{METODE PENELITIAN}

Penelitian ini menggunakan metode kuantitatif deskriptif untuk menggambarkan tingkat health literacy pasien baik fungsional, komunikatif, dan kritikal, serta metode korelasi untuk melihat faktor-faktor yang berhubungan dengan tingkat health literacy pasien. Sampel penelitian ini adalah pasien DMT2 yang berada pada wilayah kerja Puskesmas Pangolombian dan Puskesmas Kakaskasen Tomohon, mengikuti prolanis, bersedia menjadi responden dengan menandatangani surat persetujuan, dan mampu berkomunikasi. Sampel yang digunakan berjumlah 34 orang, yang ditentukan dengan menggunakan purposive sampling. Data diperoleh dengan wawancara dan menggunakan kuesioner karakteristik demografi, akses pelayanan kesehatan, akses informasi kesehatan, dan dukungan sosial, serta kuesioner Functional, Communicative, dan Critical Health Literacy (FCCHL).

Data dianalisis dengan menggunakan program SPSS 25 for windows untuk statistik deskriptif dan uji korelasi Spearman. Penelitian ini dilakukan di wilayah kerja Puskesmas Pangolombian dan Puskesmas Kakaskasen Kota Tomohon pada Juni-Juli 2018.

\section{HASIL PENELITIAN}

Tabel 1 memperlihatkan karakteristik responden dalam penelitian ini.

Tabel 1. Distribusi Karakteristik Responden

\begin{tabular}{|c|c|c|}
\hline $\begin{array}{l}\text { Karakteristik } \\
\text { Responden }\end{array}$ & $\mathrm{N}$ & $\%$ \\
\hline $\begin{array}{l}\text { Usia: } \\
34-59 \text { tahun } \\
>60 \text { tahun }\end{array}$ & $\begin{array}{l}17 \\
17\end{array}$ & $\begin{array}{l}50 \\
50\end{array}$ \\
\hline $\begin{array}{l}\text { Jenis kelamin: } \\
\text { Laki-laki } \\
\text { Perempuan }\end{array}$ & $\begin{array}{c}6 \\
28\end{array}$ & $\begin{array}{l}17.6 \\
82.4\end{array}$ \\
\hline $\begin{array}{l}\text { Suku: } \\
\text { Minahasa }\end{array}$ & 34 & 100 \\
\hline $\begin{array}{l}\text { Bahasa: } \\
\text { Bahasa Indonesia } \\
\text { Bahasa Daerah }\end{array}$ & $\begin{array}{l}24 \\
10\end{array}$ & $\begin{array}{l}70.6 \\
29.4\end{array}$ \\
\hline $\begin{array}{l}\text { Tingkat Pendidikan: } \\
\text { SD } \\
\text { SMP } \\
\text { SMA } \\
\text { DIII/Sarjana }\end{array}$ & $\begin{array}{c}17 \\
8 \\
8 \\
1\end{array}$ & $\begin{array}{c}50 \\
23.5 \\
23.5 \\
2.9\end{array}$ \\
\hline $\begin{array}{l}\text { Pekerjaan: } \\
\text { IRT } \\
\text { Swasta/Wiraswasta } \\
\text { Tani } \\
\text { PNS }\end{array}$ & $\begin{array}{c}22 \\
5 \\
5 \\
2\end{array}$ & $\begin{array}{c}64.7 \\
14.7 \\
14.7 \\
5.9\end{array}$ \\
\hline $\begin{array}{l}\text { Rata-rata penghasilan: } \\
\text { <UMP } \\
\text { > UMP }\end{array}$ & $\begin{array}{c}26 \\
8\end{array}$ & $\begin{array}{l}76.5 \\
23.5\end{array}$ \\
\hline
\end{tabular}

Rata-rata responden berusia 59 tahun dan mayoritas adalah perempuan $(82,4 \%)$. Seluruh responden merupakan suku Minahasa, dan mayoritas berbahasa Indonesia (70,6\%). Untuk tingkat pendidikan, sebagian besar responden memiliki tingkat pendidikan yang rendah yaitu hanya lulus SD (50\%), dan pekerjaan mayoritas adalah IRT $(64,7 \%)$, 
dengan penghasilan sebagian besar masih di bawah UMR (76,5\%).

Tabel 2. Distribusi karakteristik responden berdasarkan keterjangkauan akses pelayanan kesehatan, akses informasi kesehatan, dan dukungan sosial

\begin{tabular}{lcc}
\hline \multicolumn{1}{c}{ Variabel } & N & $\%$ \\
\hline $\begin{array}{l}\text { Akses pelayanan } \\
\text { kesehatan: }\end{array}$ & & \\
Sulit & 16 & $47.1 \%$ \\
Mudah & 18 & $52.9 \%$ \\
Akses informasi & & \\
kesehatan: & & \\
Rendah & 17 & $50 \%$ \\
Tinggi & 17 & $50 \%$ \\
Dukungan sosial: & & \\
Kurang & 13 & $38,2 \%$ \\
Baik & 21 & $61,8 \%$
\end{tabular}

Tabel 2 memperlihatkan distribusi keterjangkauan akses pelayanan kesehatan, akses informasi kesehatan, dan dukungan sosial berdasarkan nilai mean dan median. Sebagian besar responden menyatakan bahwa akses ke Puskesmas mudah dijangkau $(52,9 \%)$, sebagian menyatakan bahwa akses informasi kesehatan rendah $(50 \%)$, dan sebagian besar memiliki dukungan sosial yang baik $(61,8 \%)$.

Tabel 3. Distribusi Rerata Health Literacy Pasien DMT2

\begin{tabular}{lccccc}
\hline $\begin{array}{c}\text { Health } \\
\text { Literacy }\end{array}$ & Mean & Median & SD & $\begin{array}{c}\text { Min- } \\
\text { Maks }\end{array}$ & $\mathbf{9 5 \%}$ CI \\
\hline Fungsional & 1,98 & 1,50 & $\begin{array}{c}1,0 \\
0\end{array}$ & $\begin{array}{c}0,80- \\
4,00\end{array}$ & $\begin{array}{c}1,63- \\
2,33\end{array}$ \\
\hline Komunikatif & 1,66 & 1,20 & $\begin{array}{c}0,8 \\
3\end{array}$ & $\begin{array}{c}1,00- \\
3,60\end{array}$ & $\begin{array}{c}1,37- \\
1,95\end{array}$ \\
\hline Kritikal & 1,65 & 1,00 & $\begin{array}{c}0,8 \\
8\end{array}$ & $\begin{array}{c}1,00- \\
3,75\end{array}$ & $\begin{array}{c}1,33- \\
1,95\end{array}$ \\
\hline
\end{tabular}

Tabel 3 menunjukkan bahwa health literacy pasien masih cukup rendah pada semua dimensi (fungsional $(1,50 \pm 1,00)$, komunikatif $(1,20 \pm 0,83)$, dan kritikal $(1,00 \pm 0,88))$. Meskipun demikian ada juga pasien yang memiliki health literacy dengan skor maksimal pada dimensi fungsional. Dari ketiga dimensi tersebut, dapat disimpulkan bahwa skor lebih tinggi untuk fungsional dan relatif lebih rendah untuk kritikal.

Tabel 4. Hubungan karakteristik pasien dengan health literacy fungsional, komunikatif, dan kritikal

\begin{tabular}{|c|c|c|c|c|c|c|}
\hline \multirow[t]{2}{*}{ Variabel } & \multicolumn{2}{|c|}{$\begin{array}{c}\text { Literasi } \\
\text { Fungsional }\end{array}$} & \multicolumn{2}{|c|}{$\begin{array}{c}\text { Literasi } \\
\text { Komunikatif }\end{array}$} & \multicolumn{2}{|c|}{$\begin{array}{l}\text { Literasi } \\
\text { Kritikal }\end{array}$} \\
\hline & $\mathbf{r}$ & $\mathbf{p}$ & $\mathbf{r}$ & $\mathbf{p}$ & $\mathbf{r}$ & $\mathbf{p}$ \\
\hline Umur & $\begin{array}{l}- \\
0,030\end{array}$ & 0,865 & $\begin{array}{c}- \\
0,087\end{array}$ & 0,626 & $\begin{array}{c}- \\
0,019\end{array}$ & 0,915 \\
\hline $\begin{array}{l}\text { Tingkat } \\
\text { pendidikan }\end{array}$ & 0,525 & 0,001 & 0,577 & 0,000 & 0,494 & 0,003 \\
\hline Bahasa & $0, \overline{120}$ & 0,499 & $\begin{array}{c}- \\
0,111\end{array}$ & 0,531 & $\begin{array}{c}- \\
0,014\end{array}$ & 0,935 \\
\hline Pekerjaan & 0,235 & 0,181 & 0,289 & 0,097 & 0,289 & 0,098 \\
\hline Penghasilan & 0,379 & 0,027 & 0,430 & 0,011 & 0,343 & 0,047 \\
\hline $\begin{array}{l}\text { Akses } \\
\text { pelayanan } \\
\text { kesehatan }\end{array}$ & 0,458 & 0,006 & 0,415 & 0,015 & 0,339 & 0,050 \\
\hline $\begin{array}{l}\text { Akses } \\
\text { informasi } \\
\text { kesehatan }\end{array}$ & 0,692 & 0,000 & 0,676 & 0,000 & 0,556 & 0,001 \\
\hline $\begin{array}{l}\text { Dukungan } \\
\text { sosial }\end{array}$ & 0,232 & 0,187 & 0,132 & 0,457 & 0,062 & 0,729 \\
\hline
\end{tabular}

Tabel 4 memperlihatkan korelasi dan kekuatan korelasi antara karakteristik responden dengan tingkat health literacy fungsional, komunikatif, dan kritikal. Karakteristik responden yang memiliki korelasi positif dengan tingkat health literacy dan nilai $\mathrm{p}<0,05$ adalah tingkat pendidikan, penghasilan, akses pelayanan kesehatan, dan akses informasi kesehatan. Hal ini berarti, semakin tinggi tingkat pendidikan dan penghasilan seseorang maka semakin baik pula tingkat health literacynya, semakin mudah mengakses informasi kesehatan dan pelayanan kesehatan, maka semakin baik pula tingkat health literacynya.

\section{PEMBAHASAN}

Health literacy merupakan keterampilan kognitif dan sosial yang menentukan motivasi dan kemampuan 
individu untuk mendapatkan akses, memahami dan menggunakan informasi dengan cara mempromosikan dan mempertahankan kesehatan yang baik. Health literacy berarti pencapaian tingkat pengetahuan, keterampilan pribadi dan kepercayaan diri untuk mengambil tindakan untuk memperbaiki kesehatan perorangan dan masyarakat dengan mengubah gaya hidup dan kondisi kehidupan pribadi (WHO, 2018). Health literacy yang rendah dapat berpengaruh terhadap health outcomes pasien DMT2 seperti ketidakmampuan mendemonstrasikan penggunaan obat dengan benar, mengartikan etiket/ label dan informasi yang tertera pada kemasan obat (Berkman et al., 2011), serta berpengaruh terhadap kontrol glikemik yang buruk pada pasien DMT2 (Brega et al., 2012; Souza et al., 2014).

Hasil penelitian memperlihatkan bahwa tingkat health literacy responden baik fungsional, komunikatif, dan kritikal terbilang masih rendah. Hal ini disebabkan oleh beberapa faktor karakteristik responden yaitu tingkat pendidikan, penghasilan, akses pelayanan kesehatan, dan akses informasi kesehatan. Tingkat pendidikan yang dimiliki responden sebagian besar $(50 \%)$ hanya lulusan SD. Van Der Heide et al (2013) menyatakan bahwa pendidikan merupakan prediktor terkuat terhadap health literacy. Hal ini menunjukkan pentingnya pendidikan dalam membentuk health literacy seseorang. Pendidikan yang rendah merupakan prediktor untuk memiliki kesehatan dan health literacy yang rendah.

Penghasilan yang dimiliki responden sebagian besar kurang dari UMP yaitu sebesar 76,5\%. Penghasilan terkait dengan status sosial ekonomi seseorang. Penelitian dari Nölke, Mensing, Krämer, \& Hornberg (2015) mengungkapkan bahwa orang-orang dari kelas sosial atas dan menengah lebih cenderung mencari informasi kesehatan online daripada mereka dari kelas sosial yang lebih rendah. Keadaan ini bisa dijelaskan dengan perbedaan kemampuan $e$-skill dan health literacy yang kurang. Eskill mencakup keterampilan terkait media online dan keterampilan terkait informasi (strategi pencarian). Ditemukan juga bahwa kelas sosial yang lebih rendah memiliki tingkat health literacy yang rendah. Survei health literacy di Eropa (HLS-EU) mengumpulkan data dari delapan negara Eropa, termasuk sampel dari North Rhine-Westphalia (NRW), Jerman, pada tahun 2011. Temuan ini menunjukkan hubungan positif antara status pendidikan atau status sosial yang tinggi dengan tingkat health literacy (Pelikan, Röthlin, \& Ganahl, 2012).

Akses pelayanan kesehatan responden yang tergolong sulit sebesar $47,1 \%$ dan akses informasi kesehatan responden yang tergolong rendah sebesar $50 \%$. Akses pelayanan kesehatan bergantung pada sarana transportasi yang tersedia untuk mencapai pelayanan kesehatan, lokasi pelayanan, dan adanya jaminan kesehatan. Akses ini juga dipengaruhi oleh tingkat pendapatan dan mempengaruhi kemampuan seseorang untuk mendapatkan informasi kesehatan. White (2008) menemukan bahwa 80\% penduduk memiliki tingkat health literacy rendah karena tidak mendapatkan informasi dari internet.

Pada penelitian ini, akses pelayanan kesehatan sebagian besar tergolong terjangkau, ada yang dapat diakses dengan berjalan kaki, ada juga yang menggunakan kendaraan. Namun 
dalam hal ini, beberapa responden kurang menggunakan layanan kesehatan yang ada, ada juga yang menyatakan bahwa biaya transportasi ke Puskesmas relatif mahal, dan hal ini berkaitan dengan status ekonomi responden tersebut. Hal ini juga berkaitan dengan akses informasi kesehatan. Apabila responden rajin berkunjung ke Puskesmas, maka memungkinkan responden untuk memperoleh informasi kesehatan.

\section{KESIMPULAN DAN SARAN}

Hasil penelitian ini memperlihatkan gambaran tingkat health literacy pasien DMT2 di Kota Tomohon yang masih rendah (fungsional $(1,50 \pm 1,00)$, komunikatif $(1,20 \pm 0,83)$, dan kritikal $(1,00 \pm 0,88))$. Hal ini bisa terjadi karena akses informasi kesehatan yang masih kurang didapatkan oleh pasien dan juga tingkat pendidikan mereka yang masih rendah.

Saran yang dapat disampaikan bagi petugas kesehatan yaitu untuk lebih memperhatikan cara pemberian edukasi kepada pasien yang harus disesuaikan dengan tingkat pendidikan sehingga informasi yang diberikan bisa dimanfaatkan dengan baik oleh pasien.

\section{DAFTAR RUJUKAN}

American Diabetes Association (ADA). (2017). Standard of medical care in diabetes - 2017. Diabetes Care, 40 (sup 1)(January), s4-s128. https://doi.org/10.2337/dc17-S001

Balitbang Kemenkes RI. (2013). Riset Kesehatan Dasar (RISKESDAS) 2013. Retrieved November 28, 2016 , from http://www.depkes.go.id/resources /download/general/Hasil Riskesdas 2013
Berkman, N. D., Donahue, K., Berkman, N. D., Sheridan, S. L., Donahue, K. E., Halpern, D. J., \& Crotty, K. (2011). Low Health Literacy and Health Outcomes: An Annals of Internal Medicine Review Low Health Literacy and Health Outcomes: An Updated, 155(July). https://doi.org/10.1059/00034819-155-2-201107190-00005

Brega, A. G., Ang, A., Vega, W., Jiang, L., Beals, J., Mitchell, C. M., ... Roubideaux, Y. (2012). Mechanisms underlying the relationship between health literacy and glycemic control in American Indians and Alaska Natives. Patient Education and Counseling, 88(1), 61-68. https://doi.org/10.1016/j.pec.2012. 03.008

Centers for Disease Control and Prevention. (2016). Health Literacy.

International Diabetes Federation. (2017a). IDF Clinical Practice Recommendations for managing Type 2 Diabetes in Primary Care. Brussels: International Diabetes Federation.

International Diabetes Federation. (2017b). IDF Diabetes Atlas (8th ed.). Brussels: IDF.

Liu, Z., Fu, C., Wang, W., \& Xu, B. (2010). Prevalence of chronic complications of type 2 diabetes mellitus in outpatients - a crosssectional hospital based survey in urban China. Health and Quality of Life Outcomes, 8. https://doi.org/10.1186/14777525-8-62

Nölke, L., Mensing, M., Krämer, A., \& 
Hornberg, C. (2015). Sociodemographic and health(care-)related characteristics of online health information seekers: A cross-sectional German study. BMC Public Health, 15(1), 1-12. https://doi.org/10.1186/s12889015-1423-0

Pelikan, J. M., Röthlin, F., \& Ganahl, K. (2012). Comparative Report On Health Literacy in Eight EU Member States. Online Publication, 89.

Sørensen, K., Broucke, S. Van den, Fullam, J., Doyle, G., Pelikan, J., Slonska, Z., \& Brand, H. (2012). Health literacy and public health: A systematic review and integration of definitions and models. BMC Public Health, 12(80), 1-13.

Souza, J. G., Apolinario, D., Magaldi, R. M., Busse, A. L., Campora, F., \& Jacob-Filho, W. (2014). Functional health literacy and glycaemic control in older adults with type 2 diabetes: a crosssectional study. BMJ Open, 4(2), e004180.

https://doi.org/10.1136/bmjopen2013-004180

Stolar, M. (2010). Glycemic Control and Complications in Type 2 Diabetes Mellitus. American Journal of
Medicine, 123(3 SUPPL.), S3S11.

https://doi.org/10.1016/j.amjmed.2 009.12.004

Van Der Heide, I., Wang, J., Droomers, M., Spreeuwenberg, P., Rademakers, J., \& Uiters, E. (2013). The relationship between health, education, and health literacy: Results from the dutch adult literacy and life skills survey. Journal of Health Communication, 18(SUPPL. 1), 172-184.

https://doi.org/10.1080/10810730. 2013.825668

White. (2008). Assesing the nation's health literacy. Amerika Serikat: American Medical Association Foundation.

White, R. O., Wolff, K., Cavanaugh, K. L., \& Rothman, R. (2010). Addressing health literacy and numeracy to improve diabetes education and care. Diabetes Spectrum, 23(4), 238-243. https://doi.org/10.2337/diaspect.23 .4 .238

World Health Organization. (2016). Diabetes.

World Health Organization. (2018). Health promotion. 